\title{
Experimental vaccine against Pseudomonas pseudomallei infections in captive cetaceans
}

\author{
Neylan A. Vedros ${ }^{1}$, Derek Chow ${ }^{2}$, Edgar Liong ${ }^{3}$ \\ ${ }^{1}$ School of Public Health, Dept Biomedical and Environmental Health Sci., University of California, Berkeley, California 94720 , \\ USA \\ ${ }^{2}$ Ocean Park Corp., Hong Kong \\ ${ }^{3}$ China Wildlife Conservation Corp., Hong Kong
}

\begin{abstract}
The antibody response to an experimental acellular Pseudomonas pseudomallei vaccine was evaluated by Enzyme Immunoassay in captive cetaceans at Ocean Park, Hong Kong. The vaccine preparation consisted of a protein-polysaccharide (1:3) mixture with trace nucleic acids and no 2-keto-3deoxyoctonate. An initial dosage of $500 \mu \mathrm{g}$ carbohydrate for newly arrived dolphins Tursiops aduncus and false killer whales Pseudorca crassidens in 1987 and $1 \mathrm{mg}$ carbohydrate for other long-term resident animals (1983 to 1988) followed by $500 \mu \mathrm{g}$ boosters at ca 6 to $10 \mathrm{wk}$ intervals for all animals maintained high specific antibody levels. Mortality due to melioidosis was reduced over a 5 yr period from $45 \%$ to less than $1 \%$.
\end{abstract}

\section{INTRODUCTION}

Pseudomonas pseudomallei is the etiologic agent of melioidosis, a disease principally of rodents but also occasionally of humans. The microorganism is indigenous in the soil and water of southeast Asia and infections in humans occur via the respiratory tract or through contaminated wounds and abrasions (Vedros 1988).

Captive animals appear to be susceptible to melioidosis in southeast Asia, and this has been particularly true of captive cetaceans in Hong Kong (Liong et al. 1985). The highest mortality occurs during the rainy season (May-Oct). During this period considerable amounts of soil are washed down from mountains into bays adjacent to Hong Kong island. Some of these bays are used as a source of water for the Ocean Park cetacean pools. Further, the animals are under stress due to high winds and heavy rainfall.

In 1983 a vaccine trial was initiated using an acellular preparation of Pseudomonas pseudomallei. This report describes the antibody response to the experimental vaccine in 5 species of cetaceans. Antibody levels are presented for 1 group of animals during the rainy season in 1987, 1 group during the dry, fall season (1987 to 1988), and animals representative of those resident during the 5 yr vaccine trial.

\section{METHODS AND MATERIALS}

Microorganisms. Strain SLT Pseudomonas pseudomallei was isolated in 1982 from lung tissue in a fatal melioidosis case (dolphin Tursiops aduncus) on Brain Heart Infusion agar (BHI; Difco Co., Detroit, MI, USA) containing 1:200 000 crystal violet and 1\% gentamycin. This strain was used for preparation of the vaccine and antigen in the Enzyme Immunoassay (EIA) in this study although 19 other strains were isolated from tissues in fatal melioidosis cases of 1 stellar sea lion Eumetopias jubata, 1 northern fur seal Callorhinus ursinus, 11 Tursiops aduncus, and 6 Tursiops gilli. All strains belonged to serological Type 1. Initial biochemical and morphological criteria for identification were essentially as described by Dodin \& Galimond (1976) and listed in Table 1 . The final step in the identification was agglutination with a specific anti-Type I $P$. pseudomallei serum kindly supplied by Dr Paul Martin of the Institut Pasteur. All strains were maintained in lyophile form at $4{ }^{\circ} \mathrm{C}$ in their third passage from the source.

Vaccine preparation. The acellular vaccine was prepared by a modification of the method for isolating surface components of Neisseria meningitidis as described by Apicella (1976). Strain SLT was grown overnight at $36^{\circ} \mathrm{C}$ on $\mathrm{BHI}$ agar plates containing $1 \%$ 
Table 1. Morphological/biochemical reactions used to identify Pseudomonas pseudomallei

\begin{tabular}{ll|}
\hline \multicolumn{1}{|c|}{ Test } & \multicolumn{1}{c}{ Reaction } \\
\hline Staining & Gram negative rod; bipolar staining \\
Motility & Posititve \\
Nitrate reduction & Positive to nitrite \\
Growth on McConkey's agar & Positive \\
Urease & Negative \\
Simmon's citrate & Positive \\
Gelatin liquifaction & Positive \\
Arginine dihydrolase & Positive \\
Poly- $\beta$-hydroxybutyrate accumulation & Positive \\
OF-Maltose & Oxidizer positive; fermentation negative \\
\hline
\end{tabular}

glycerol. Bacteria were harvested with BHI broth and inoculated into 121 of BHI broth containing $1 \%$ glycerol. Final concentration was approximately $10^{6}$ bacteria $\mathrm{ml}^{-1}$. After $48 \mathrm{~h}$ stationary growth $\left(36^{\circ} \mathrm{C}\right)$ the pellicle was disrupted by shaking with sterile glass beads (10 to $12 \mathrm{~mm}$ diameter, $70 \mathrm{~g} \mathrm{l}^{-1}$ ) for $72 \mathrm{~h}$ at room temperature. Bacteria and beads were removed by centrifugation $(7000 \times \mathrm{g}, 20 \mathrm{~min})$ and formalin added to the supernatant $(0.1 \%$ final concentration). After $48 \mathrm{~h}$ at $4{ }^{\circ} \mathrm{C}$, dry ammonium sulfate $\left(540 \mathrm{~g} \mathrm{l}^{-1}\right)$ was slowly added, stirred for $24 \mathrm{~h}\left(4^{\circ} \mathrm{C}\right)$ and precipitate was solubilized in distilled water and extensively dialysed against distilled water until ammonium ions were removed. The dialysate was concentrated 10-fold (Amicon, PM-30 membrane) and adjusted to $\mathrm{pH} 11$ with $1.0 \mathrm{~N}$ $\mathrm{NaOH}$. After $1 \mathrm{~h}$ at room temperature the $\mathrm{pH}$ was adjusted to 7.0 with $0.1 \mathrm{~N} \mathrm{NCl}$. The precipitate was removed by centrifugation $(20000 \times g, 30 \mathrm{~min})$ and the supernatant, after equilibration, added to a column of Sepharose Cl-4B gel (Pharmacia, $100 \times 2.5 \mathrm{~cm}$ ). The fractions were eluted with $0.02 \mathrm{M}$ phosphate buffer, $\mathrm{pH}$ 6.5. The carbohydrate containing fractions were pooled, ethanol added to a final concentration of $25 \%$ and precipitate removed after $2 \mathrm{~h}$ stirring at room temperature. The alcohol was removed from the supernatant under vacuum. The final vaccine was lyophilized, stored at $4{ }^{\circ} \mathrm{C}$ and when needed reconstituted with sterile distilled water. An immunizing dose of the vaccine (1 $\mathrm{mg}$ of carbohydrate) contained $259 \mu \mathrm{g}$ of protein, trace nucleic acid, and no 2-keto-3-deoxyoctonate.

IgG isolation. The IgG of the pooled sera from 6 Tursiops aduncus was isolated through a column of DEAE AFFI GEL BLUE as described by the manufacturer (Biorad, Richmond, CA, USA, 1988).

Rabbit antisera. Rabbit anti-IgG was produced by subcutaneous (s.c.) injection of $1.0 \mathrm{mg}$ IgG mixed in equal volume of Complete Freund's Adjuvant (Difco Co., Detroit, MI, USA) followed by a booster 3 wk later of $1.0 \mathrm{mg} \mathrm{IgG}$ in Incomplete Adjuvant (s.c.). Rabbits were bled 7 d later.

Rabbit antisera to the vaccine antigen was produced by a similar procedure as above using $2.0 \mathrm{mg}$ carbohydrate. A third booster of $3.0 \mathrm{mg}$ carbohydrate without adjuvant was given intravenously (i.v.) 3 wk later and the rabbits bled $10 \mathrm{~d}$ later. All sera were stored at $-20^{\circ} \mathrm{C}$.

Assay of vaccine in hamsters. Three groups of 6 hamsters each (av. wt $126 \mathrm{~g}$ ) were injected subcutaneously (s.c.) in $0.2 \mathrm{ml}$ aliquots with 10,50, and $100 \mu \mathrm{g}$ of vaccine (carbohydrate) respectively and boosted $3 \mathrm{wk}$ later with similar dosages s.c. Controls received $0.2 \mathrm{ml}$ saline s.c. The animals were challenged 10 d later with 20 Minimal Lethal Doses (MLD) of Strain SLT Pseudomonas pseudomallei and death recorded over a $7 \mathrm{~d}$ period. Pure cultures of $P$, pseudomallei were isolated from the spleen, liver, and blood of those hamsters that died.

Enzyme immunoassay (EIA). Procedures and reagents were as previously described (Suer et al. 1988). The vaccine was solubilized in bicarbonate buffer ( $\mathrm{pH} 9.6$ ) and the optimum concentration $\left(125 \mathrm{ng} \mathrm{ml}^{-1}\right.$ carbohydratel to coat the EIA plates determined by block titration against rabbit antisera to the vaccine. Optimum serum dilution $(1: 200)$ was determined by block titration of the pooled sera of 4 Tursiops aduncus that were positive (optical density, O. D. $=>1.0$ ) by the EIA to the vaccine antigen and the pooled sera of $2 \mathrm{~T}$. gilli that were negative $(O . D .=<0.2$ ). Both positive and negative serum controls were included in every test.

Optimum dilutions of rabbit anti-dolphin Ig $\mathrm{G}$ and goat anti-rabbit IgG ( $\mathrm{H} \& \mathrm{~L}$ chains) horseradish peroxidase conjugate (Zymed Labs., San Francisco, CA, USA) were determined using $10 \mu \mathrm{g} \mathrm{m} \mathrm{m}^{-1}$ of purified dolphin $\mathrm{IgG}$.

Cetacean immunization. One group of 9 false killer whales Pseudorca crassidens that arrived in April 1987 were injected intramuscularly (i.m.) with $500 \mathrm{ug} \mathrm{car-}$ bohydrate (1.8 to $2.2 \mu \mathrm{g} \mathrm{kg}{ }^{-1}$ ) and boosted with $500 \mu \mathrm{g}$ carbohydrate i.m. in June and August except as noted. Another group of 8 bottlenose dolphins Tursiops aduncus that arrived in November 1987 were injected i.m. with $500 \mu \mathrm{g}$ carbohydrate $\left(2.3\right.$ to $\left.3 \mu \mathrm{g} \mathrm{kg}^{-1}\right)$ and boosted i.m. with $500 \mu \mathrm{g}$ carbohydrate in December

Four Tursiops gilli that arrived in March 1986 were 
injected i.m. with $1 \mathrm{mg}$ carbohydrate (1.7 to $\left.3 \mu \mathrm{g} \mathrm{kg}^{-1}\right)$ and boosted i.m. with $500 \mu \mathrm{g}$ carbohydrate in midAugust.

The other cetaceans (6 Tursiops aduncus, 1 Lagarenchus obliquidens, 1 Orcinus orca) resident in Ocean Park from 1983 to 1988 were injected i.m. yearly with $1 \mathrm{mg}$ carbohydrate in the spring (Mar-Apr) and boosted i.m. with $500 \mu \mathrm{g}$ carbohydrate in July or August and then again in either September, October or November.

Chemical analyses. Proteins were determined as described by Lowry et al. (1951) using bovine serum albumin as standard. Carbohydrates were determined as described by Dubois et al. (1956), using glucose as standard. Nucleic acids were determined at $O D_{260}$ and $\mathrm{OD}_{280}$ in a Model 552 Perkins-Elmer scanning spectrophotometer. Determination of 2-keto-3-deoxyoctonate was by the thiobarbituric acid assay as described by Osborne (1963).

\section{RESULTS}

\section{Vaccine}

The yield of vaccine averaged $22 \mathrm{mg}$ carbohydrate per liter of culture. Yield per liter was less ( 3 to $12 \mathrm{mg}$ $1^{-1}$ ) in 2 experiments where cultures were not stationary, but incubated on a gyrorotary shaker (120 rpm). Further detailed chemical analysis of the vaccine components is in progress.

At dosages above $20 \mu \mathrm{g}$ carbohydrate (initial injection plus 1 booster) the vaccine protected 10 out of 12 hamsters challenged with 20 MLD of strain SLT Pseudomonas pseudomallei (Table 2). Protection did not increase with immunizations above $50 \mu \mathrm{g}$ carbohydrate (total).

\section{Immune response in false killer whales}

The EIA antibody levels in 3 of 9 false killer whales Pseudorca crassidens from their arrival at Ocean Park

Table 2. Protective effect of Pseudomonas pseudomallei vaccine in hamsters. Vaccine lot \#86-11. Animals boostered with same dosage $3 \mathrm{wk}$ after primary immunization and challenged $10 \mathrm{~d}$ later with $20 \mathrm{MLD}$. Death observed over $7 \mathrm{~d}$ period

\begin{tabular}{|ccc|}
\hline Group & $\begin{array}{c}\text { Vaccine dosage } \\
(\mu \mathrm{g})\end{array}$ & $\begin{array}{c}\text { Number of animals } \\
\text { dead/survivors }\end{array}$ \\
\hline 1 & 10 & $5 / 1$ \\
2 & 50 & $1 / 5$ \\
3 & 100 & $1 / 5$ \\
4 & Saline & $6 / 0$ \\
"Six animals per group & \\
\hline
\end{tabular}

in April 1987 through September 1987 are shown in Fig. 1a. The booster injections of $500 \mu \mathrm{g}$ carbohydrate in June and August maintained antibody levels throughout the rainy season. Four other false killer had similar antibody levels. Two other individuals had relatively low antibody levels in June, consequently the second booster in August was increased to $1 \mathrm{mg}$ carbohydrate. Antibody levels rose similarly to those in the other 7 false killer whales (Fig. 1b)

\section{Immune response in dolphins}

Representative EIA antibody levels in 3 of 8 Tursiops aduncus from their arrival on 3 November 1987 through 7 January 1988 are shown in Fig. 2. The range of EIA values for all 8 individuals prior to immunization was O. D. $=0.146$ to 0.347 . All $T$. aduncus received a primary injection i.m. of $500 \mu \mathrm{g}$ carbohydrate on 3 November 1987 and a booster injection of $500 \mu \mathrm{g}$ car-
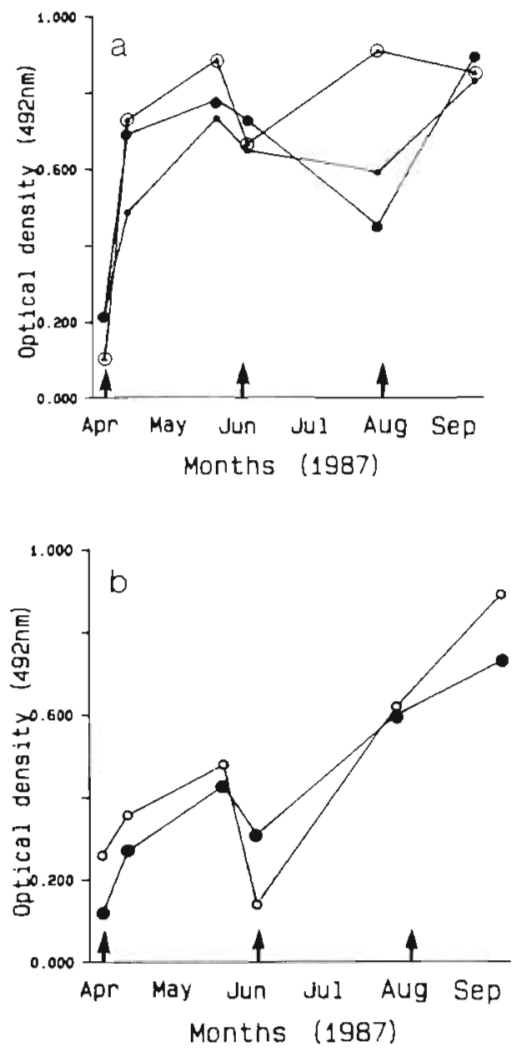

Fig. 1. Enzyme immunoassay (EIA) antibody levels in Pseudoorca crassidens. (a) EIA values for 3 individuals (representative of a group of 7 ) through the rainy season (Apr-Dec) 1987. (b) Two individuals of the same group with lower antibody levels after immunization. Arrows: dates of immunization 


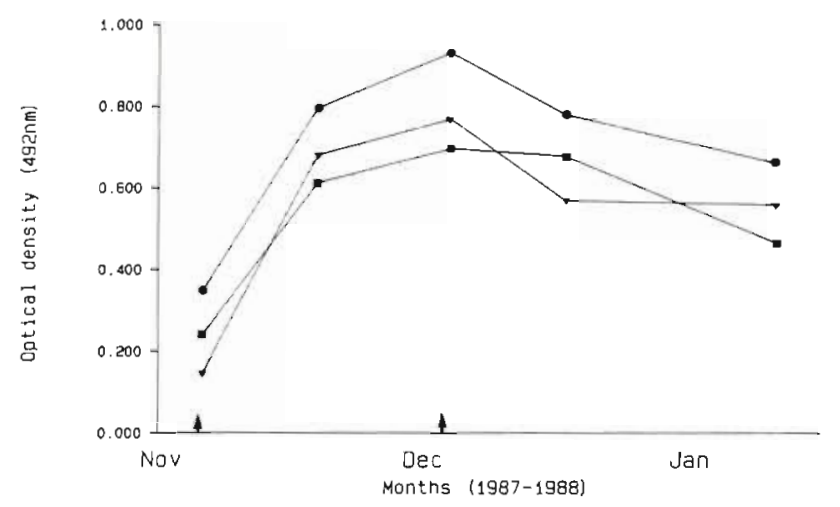

Fig. 2. Enzyme immunoassay antibody levels of 3 Tursiops aduncus, representative of a group of 8 , during winter (Nov-Jan 1988). Arrows: dates of immunization

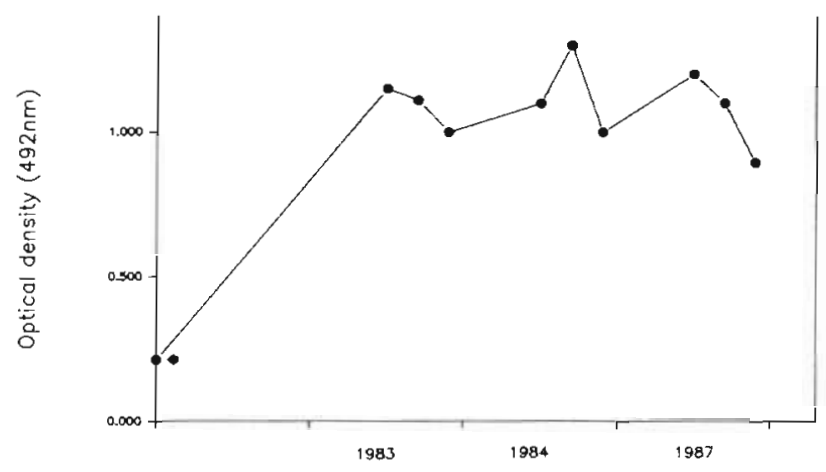

Fig. 3. Enzyme immunoassay antibody levels in 1 Tursiops aduncus, representative of 7 individuals, resident in Ocean Park 1983-1988. Initial antibody levels (arrow) is from the individual at capture in March 1982. Other antibody values were from bleedings in April, August and November of the years indicated. See 'Methods and Materials' for dates of immunization

bohydrate on 3 December 1987 . The booster injection did not cause an increase in antibody levels.

The other resident dolphins (6 Tursiops aduncus, 1 Lagarenchus obliquidens) had essentially the same or higher EIA antibody levels during the $5 \mathrm{yr}$ period of the vaccine trial as shown for the false killer whales in Fig. 1a (O. D. $=0.4$ to 1.2$)$. A representative example of 1 T. aduncus EJA antibody levels during 1983, 1984, and 1987 are shown in Fig. 3.

Four Tursiops gilli died from acute melioidosis during their first year of captivity (1986). Necropsis revealed pathology and microbiology consistent with diagnosis of melioidosis as previously reported (Liong et al. 1985). EIA values for 2 of these 4 individuals are shown in Fig. 4. Initial antibody levels to Pseudomonas pseudomallei a few days after capture, prior to immunization, and while the animals were still in the waters off the coast of Japan, were low. Antibody levels rose after initial immunization with $1 \mathrm{mg}$ of the strain SLT P.

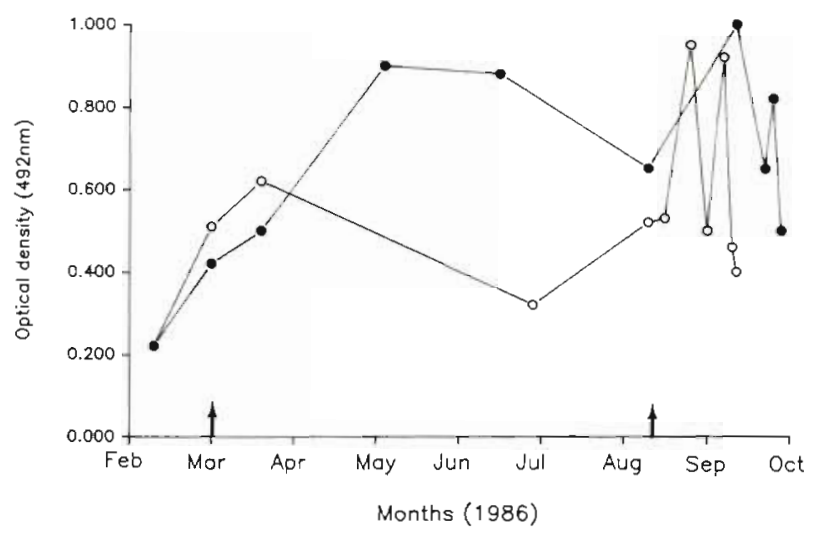

Fig. 4. Enzyme immunoassay antibody levels of 2 Tursiops gilli that died of melioidosis during their first year of captivity in 1986. Arrows: dates of immunization

pseudomallei vaccine (March) and were maintained during the rainy season with a single booster injection of $500 \mathrm{\mu g}$ carbohydrate in mid-August. Antibody levels then dropped precipitously a few days later, rose the following day, then dropped at death $2 \mathrm{~d}$ later.

\section{Immune response in a killer whale}

A single resident killer whale Orcinus orca received an annual (Apr) injection of $1 \mathrm{mg}$ carbohydrate $(0.3$ to $0.5 \mu \mathrm{g} \mathrm{kg}^{-1}$ ) and boosters of $500 \mu \mathrm{g}$ in July and September during a 5 yr period. At the start of the vaccine trial in 1983 the ElA antibody level was very high; $(O . D .=1.55)$ and this high range (O. D. 1.3 to 1.6$)$ has been maintained to now.

\section{DISCUSSION}

Pseudomonads are ubiquitous in the environment and difficult to speciate (Redfern et al. 1966, Palleroni 1984). Biochemical/morphological criteria indicate that the Pseudomonas species most similar to $P$. pseudomallei are $P$. mallei (etiological agent of glanders), and P. carophyllia (a plant pathogen). Further, in one laboratory-acquired case of melioidosis, $P$. pseudomallei was mistaken for $P$. cepacia, a common bacterial inhabitant of humans (Schlech et al. 1981). In the present study there was no difficulty in isolating pure cultures of $P$. pseudomallei from the tissues of animals that died of melioidosis using crystal violet and gentamycin as selective inhibitors.

An extensive study is now in progress to determine the foci of Pseudomonas pseudomallei in the environment at Ocean Park. During the rainy season cultures of soil from multiple sites, fish preparation rooms, rainwater, etc. contained many saprophytic bacteria and fungi which readily grew on the selective medium 
being used. Other selective inhibitors are being evaluated to facilitate this study.

There is no available vaccine for melioidosis either in humans or other animals. Extensive serosurveys of humans in SE Asia indicate very high rates of subclinical infections (Nigg 1963) but rare acute infections. Pseudomonas pseudomallei is not a very invasive pathogen (Redfern et al. 1966) but can readily cause disease whether in war wounds (Vietnam) (Weber et al. 1969) or when water is aspirated during drowning (Achana et al. 1985, Lee et al. 1985).

Only recently has it been recognized that, in Asia, captive animals such as gorillas, deer, and particularly cetaceans are susceptible to melioidosis during specific times of the year (Vedros et al. 1983). Prior to 1983 a sonicated lysate preparation of several strains of $P$ seudomonas pseudomallei was first tested as a vaccine. The strains included those from the elephant seal, and 6 from Tursiops aduncus including strain SLT. The lysate was effective in protecting hamsters experimentally and produced high levels of complement fixing antibodies in pinnipeds and cetaceans but was very toxic for cetaceans. This toxicity, as observed by the authors and animals trainers, consisted of reduced food intake, lethargy, erratic behavior and refusal to participate in any behaviour patterns for several days. The sonicated lysate vaccine preparation caused no side reactions in pinnipeds.

This report describes a vaccine which consists of a protein-polysaccharide mixture (1:3), as yet not fully defined chemically, which produced no side reactions in cetaceans, was effective in protecting hamsters experimentally, induced high levels of specific antibodies, and has reduced mortality in cetaceans due to Pseudomonas pseudomallei from $45 \%$ in 1983 (D. D. Hammond pers. comm.) to less than $1 \%$ in 1988.

We have no explanation for the death in 1986 of the 4 Tursiops gilli with high levels of antibodies (Fig. 4) nor for the erratic antibody behaviour prior to death. It may be that these dolphins had foci of internal chronic lesions consistently noted at necropsy in animals that died of melioiodosis (Liong et al. 1985). Pseudomonas pseudomallei could then be released into the blood stream. Another possibility is that these dolphins were subjected to a massive challenge of $P$. pseudomallei in the water, and/or possibly compromised by severe stress. The current speculation is that $P$. pseudomallei is an opportunist, concentrated in the cetacean environment during the rainy season in Ocean Park, and may play a role in the terminal illness of animals compromised by other infections. In $1 T$. aduncus that died in 1988 there was evidence of viral hepatitis by histology, yet $P$. pseudomallei was isolated from many tissues
(Jay Sweeney pers. comm.). Studies on environmental sources of $P$. pséudomallei, appropriate dosages of vaccine, and optimum time intervals of immunization are in progress.

Acknowledgements. The authors thank the staff of the Marine Sciences Laboratory, Ocean Park (Hong Kong), and J. P. Zhang and Hsia-Lai Liu for excellent assistance. This work was supported by a grant from Ocean Park Corp., Hong Kong.

\section{LITERATURE CITED}

Achana, V., Silpapojakul, K., Thininta, W., Kalanowakul, S. (1985). Acute Pseudomonas pseudomallei pneumonia and septicemia following aspiration of contaminated water: a case report. SE Asian J. Trop. Med. Pub. Hlth 16: 500-504

Apicella, M. A. (1976). Immunological and biochemical studies of meningococcal C polysaccharide isolated by diethylaminoethyl chromotography. Inf. Immun. 14: 106-113

Dodin, A., Galimond, M. (1976). Le bacille de Whitmore. Rec. Med. Vet. 152: 323-325

Dubois, M., Gilles, K. A., Hamilton, J. K. (1956). Colorimetric method for determinations of sugars and related substances. Analyt. Chem. 28: 350-356

Lee, N., Wu, J.-L., Lee, C.-H., Tsai, W.-C. (1985). Pseudomonas pseudomallei infection from drowning. The first reported case in Taiwan. J. Clin. Microbiol. 23: 352-354

Liong, E., Vedros, N. A., Hammond, D. D. (1985). Pseudomonas pseudomallei infection in a dolphin (Tursiops gilli): a case report. Aquat. Mamm. 1: 20-22

Lowry, O. H. Rosebrough, N. J., Farr, A. L., Randall, R. J. (1951). Protein measurements with the Folin phenol reagent. J. Biol. Chem. 193: 265-275

Nigg, C. (1963). Serologic studies on subclinical melioidosis. J. Immunol. 91: 18-28

Osborne, M. J. (1963). Studies on the gram negative cell wall. I. Evidence for the role of 2-keto-3-deaxyoctonate in the lipopolysaccharide of Salmonella typhimurium. Proc. natn. Acad. Sci. 50: 499-506

Palleroni, N. J. (1984). The pseudomonads. In: Krieg, N. R., Holt, J. G. (eds.) Bergey's Manual of systematic bacteriology, Vol 1 Williams and Wilkens, Baltimore, p. 141

Redfern, M. S., Palleroni, N. J., Stanier, R. Y (1966). A comparative study of Pseudomonas pseudomallei and Bacillus mallei. J. gen. Microbiol. 43: 293-313

Schlech, W. F., Turchick, J. B., Westlake, R. E., Klein, G. C., Bond, J. D., Weaver, R. E. (1981). Laboratory-acquired infection with Pseudomonas pseudomallei (melioidosis). N. Engl. J. Med. 305: 1133-1135

Suer, L. D., Vedros, N. A., Schroeder, J. P., Dunn, J. L. (1988). Erysipelothrix rhusiopathiae. II. Enzyme immunoassay of sera from wild and captive marine mammals. Dis. Aquat. Org. $5: 7-13$

Vedros, N. A., Liong. E., Hammond, D. D. (1983). A potential vaccine for melioidosis in marine mammals. Proc. 14 th Annual Conf. Intl Assoc. Aquatic An. Med., p. 17

Vedros, N. A. (1988). Melioidosis and glanders, In: Ballows, A., Hausler, W. J., Lennette, E. H. (eds.) Laboratory diagnosis of infectious diseases. Theory and practice, Chap. 38 Springer-Verlag, New York, p. 951-992

Weber, D. R., Douglas, L. E., Brundage, W G., Stallkamp, T C. (1969). Acute varieties of melioidosis occurring in US soldiers in Vietnam. Am. J. Med. 46: 234-244 